\title{
$\begin{array}{lllllllllllllllll}\mathbf{S} & \mathbf{A} & \mathbf{M} & \mathbf{M} & \mathbf{L} & \mathbf{U} & \mathbf{N} & \mathbf{G} & & \mathbf{T} & \mathbf{U} & \mathbf{S} & \mathbf{C} & \mathbf{U} & \mathbf{L} & \mathbf{U} & \mathbf{M}\end{array}$
}

In Tusculum, vor den Toren Roms, hatte Cicero sein Landhaus.

In Zeiten der Muße, aber auch

der politischen Isolation, zog er sich dorthin zurück.

Tusculum wurde zum Inbegriff für

Refugium, fur Muße, für wertvolle

Fluchten aus einem fordernden Alltag.

In der ersten Phase des

Rückzugs aus der Politik schrieb

Cicero in Tusculum die sogenannten

Tuskulanen, eine lateinische

Einfuhrung in die Welt

der (griechischen) Philosophie.

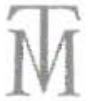

Herausgeber:

Niklas Holzberg

Rainer Nickel

Karl-Wilhelm Weeber

Bernhard Zimmermann 

LUKREZ

VON DER NATUR

Lateinisch - deutsch

Herausgegeben und übersetzt von

Hermann Diels

Mit einer Einfuhrung und

Erläuterungen von

Ernst Günther Schmidt

und einem Geleitwort von

Albert Einstein

3. Auflage 2013 
Bibliografische Information der Deutschen Nationalbibliothek Die Deutsche Nationalbibliothek verzeichnet diese Publikation in der Deutschen Nationalbibliografie; detaillierte bibliografische Daten sind im Internet über http://dnb.d-nb.de abrufbar.

\section{Auflage 2013}

(C) Akademie Verlag GmbH, Berlin 2013

Ein Wissenschaftsverlag der Oldenbourg Gruppe

Einführung und Erläuterungen wurden mit freundlicher Erlaubnis des Deutschen Taschenbuch Verlags GmbH (C 1991) übernommen.

wwwakademie-verlag.de

Das Werk einschließlich aller Abbildungen ist urheberrechtlich geschützt. Jede Verwertung außerhalb der Grenzen des Urheberrechtsgesetzes ist ohne Zustimmung des Verlages unzulässig und straftar. Das gilt insbesondere für Vervielfältigungen, Übersetzungen, Mikroverfilmungen und die Einspeicherung und Bearbeitung in elektronischen Systemen.

Einbandgestaltung: Gabriele Burde, Berlin Satz: Filmsatz Pfeifer, Gräfelfing b. München Druck und Bindung: Pustet, Regensburg

Dieses Papier ist alterungsbeständig nach DIN/ISO 9706

ISBN 978-3-05-006392-8 